\title{
Confirmed presence of the squash bee, Peponapis pruinosa (Say, 1837) in the state of Oregon and specimen-based observational records of Peponapis (Say, 1837) (Hymenoptera: Anthophila) in the Oregon State Arthropod Collection
}

\author{
Lincoln R. Best ${ }^{1}$, Christopher J. Marshall ${ }^{1}$ and Sarah Red-Laird ${ }^{2}$
}

${ }^{1}$ Oregon State Arthropod Collection, Department of Integrative Biology, Oregon State University, Corvallis OR 97331

${ }^{2}$ The Bee Girl Organization, PO Box 3257, Ashland, OR 97520

Cite this work as:

Best, L. R., C. J. Marshall and S. Red-Laird. 2019. Confirmed presence of the squash bee, Peponapis pruinosa (Say, 1837) in the state of Oregon and specimen-based observational records of Peponapis (Say, 1837) (Hymenoptera: Anthophila) in the Oregon State Arthropod Collection. Catalog: Oregon State Arthropod Collection. 3(3) p 2-6 DOI: http://dx.doi.org/10.5399/osu/cat osac.3.3.4614

\section{Abstract}

A new Oregon record for Peponapis pruinosa (Say, 1837) is presented with notes on its occurrence and photographs. This record provides the first empirical evidence of the genus and species in the state of Oregon. A dataset of Peponapis (Say, 1837) specimens in the holdings of the Oregon State Arthropod Collection is included with a brief summary of its contents.

\section{Introduction}

Bees of the genus Peponapis (Say, 1837) (Apidae: Eucerini) are known pollen-collecting specialists of Cucurbita Linnaeus, a genus of plants containing native species occurring in Central America, Mexico and the southwestern United States of America (Hurd and Linsley 1964; Hurd et al. 1971). Domesticated Cucurbita species, including pumpkins, summer and fall squashes, marrows, and many other varieties, are widespread throughout North America, and have allowed members of the genus to expand their geographic range (López-Uribe et al. 2016) Accounts of individual bees visiting other flowers exist (e.g., Ipomea), but the bees were not seen to collect pollen (Mathewson 1968).

In recent years, perhaps as an offshoot to honey bee decline, the visibility and importance of honeybees as well as native pollinators has grown both within the scientific community as well as the public at large (Allchin 2018). Much of the justification for this interest centers on the ecological and agricultural services provided by bees and other pollinators, however biological conservation of these species for their own sake is also championed (Kleijn et al. 2015; Matias et al. 2017). No matter the underlying justification, a key challenge to assessing pollinator health is a disconnect between a small and highly specialized community of bee taxonomists and the broader community who wish to know more about their local pollinators. Unlike wild plants, birds or even a few large and showy insects (e.g., butterflies and dragonflies), many bee groups lack available and comprehensive diagnostic tools to identify genera and species, or the existing tools require extensive knowledge of bee anatomy and terminology.

This is particularly true of the Pacific Northwest (PNW) region of North America where the native bee fauna has received comparatively less study than other parts of the US and Canada. The Oregon Bee Project is a multi-institutional partnership to develop and expand taxonomic knowledge of 
PNW bees through formal programs training citizen scientists to survey, identify and voucher the bees of our region. This paper represents the type of discovery that can be made when trained and interested members of the public (citizen scientists) have the capacity to work with professional scientists and compare their observations to historical records reported in scientific literature and stored in scientific research collections.

\section{New state record}

The Oregon populations of Peponapis were first noted by Sarah Red-Laird (SRL) in 2016 when a young participant in a Bee Biology Camp she was leading noted a 'flat honeybee' in a squash flower. Recognizing that the bee was unusual (e.g., not a honeybee), SRL, took some photos and a specimen and later used online guides (www.bugguide.net) to determined that the bee was Peponapis pruinosa. Given that the bees were abundant on the organic farm where the camp took place, and that the P. pruinosa is widely distributed in North America, SRL did not realize the species had not yet been confirmed to occur in Oregon.

Two years later, at a bee taxonomy workshop (Oregon Bee School) led by Lincoln R. Best (LRB) species were discussed that were potentially in the state, but that had not yet been confirmed. At that time the importance of these earlier observations was recognized. New material (collected in 2018) was sent to Corvallis to confirm the identification and deposit a voucher in the OSAC (Figure 1).

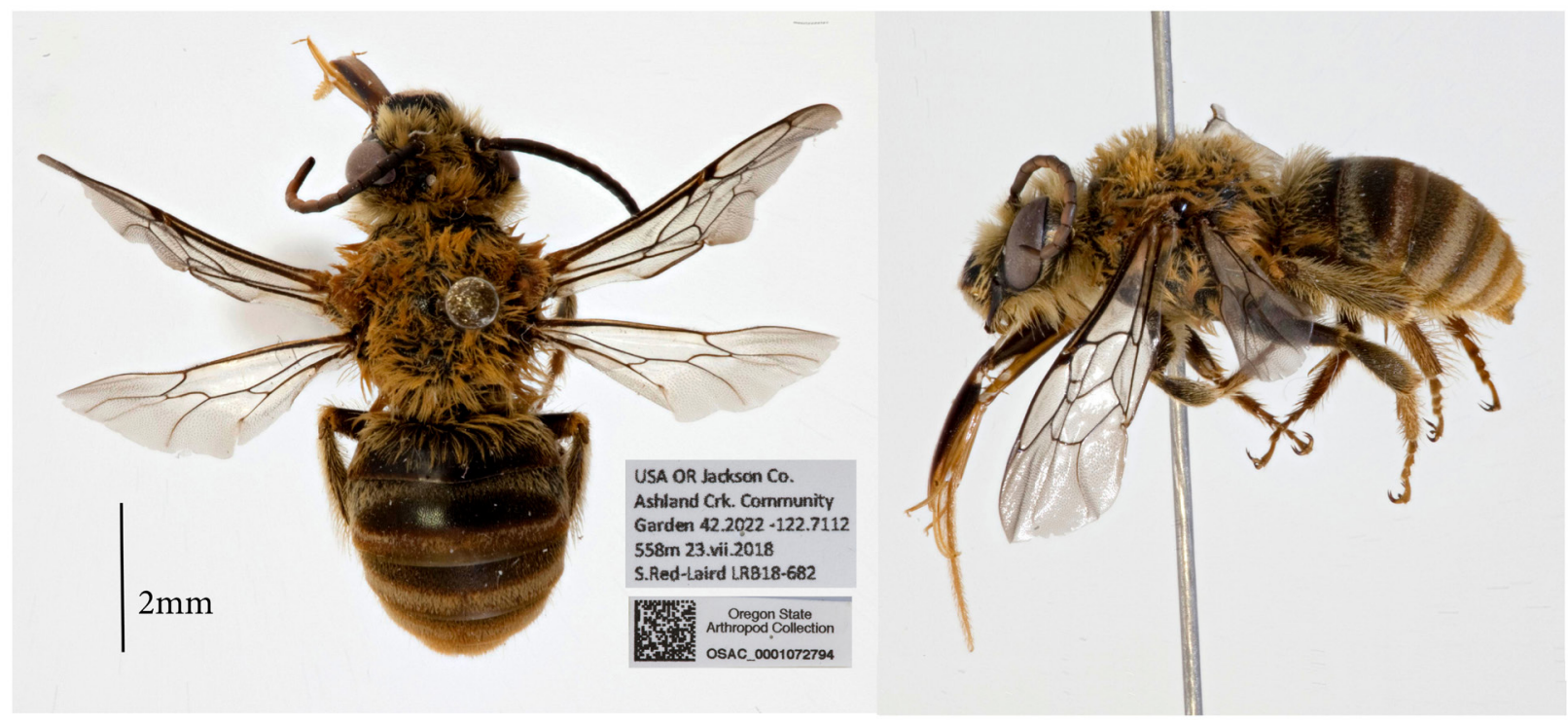

Figure 1. Voucher specimen of Oregon Peponapis pruinosa. OSAC_0001072794

Efforts were then made to find other Oregon historical records of Peponapis in the OSAC, other collections, literature and online data portals (Global Biodiversity Information Facility GBIF, iNaturalist, Bugguide, etc). No other confirmed records could be found at this time. 


\section{Three mis-transcribed specimen records}

Originally three putative older records, from 1933, were retrieved from GBIF based on specimens housed at the Snow Entomological Collection (Kansas University; catalog \#'s 442547-442549) (Thomas 2019). The digitized records indicate the specimens were all collected in late July from Andover, Oregon by an unknown collector and georeferenced as 45.33139 -122.2278, coordinates that correspond to Eagle Creek, Oregon. There is no Andover, Oregon reported in the US Geological Society Gazetteer (https:/ / geonames.usgs.gov; (McArthur and McArthur 2003).

A search for other bee specimen records from Andover and the years around 1933 yield additional KU specimens, with photographed labels reading “Andover, O” (Figure 2), a label that should correctly be geo-referenced in Ohio. Zach Fallin, collection manager for KU confirmed the Peponapis labels match these others (personal communication), and are therefore also from Ohio; and while they do not bear a collector's name it also seems reasonable to assume they were likewise collected by the then 20 year old Harold Rodney Dodge, who grew up in the vicinity of Columbus Ohio and would later become a professional entomologist specializing on Diptera (Telford and James 1973). The records have been updated, but we are reporting the update herein in case the online records were included in other derivative datasets / publications.

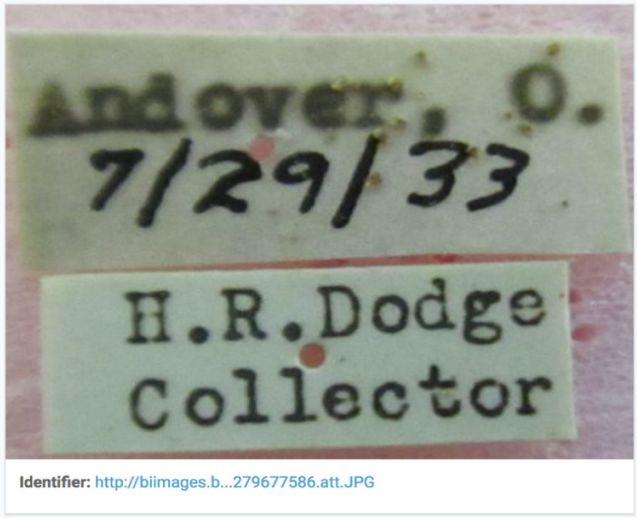

Figure 2. Historical specimen labels from KU bee specimens from Andover, $\mathrm{O}$.

\section{Additional Peponapis records}

In addition to these two Oregon records, we provide the label data for all the material currently housed at the OSAC. All specimens were determined (or redetermined) by Lincoln R. Best using keys produced by Ayala and Griswold (2012). There are 26 specimens from 4 species in the collection. The collection has 2 of the 6 known species that occur in the US ( $P$. pruinosa and $P$. timberlaki), in addition to a Mexican species ( $P$. smithi) and the South American species: $P$. fervens (Table 1$)$.

Table 1. Summary of digitized Peponapis specimens

\begin{tabular}{|l|l|}
\hline Species & Geographic origin of OSAC material \\
\hline P. pruinosa & California, Nevada, Pennsylvania, Oregon \\
\hline P. timberlaki & Arizona \\
\hline P. fervens & Argentina \\
\hline P. smithi & Mexico \\
\hline
\end{tabular}

\section{Digitization methods}

Each recorded specimen is affixed with unique identifier that is printed both as a machine-readable data matrix barcode and a human readable numeral. These identifiers are printed with archival ink on acid free cardstock and place on the specimen pin. Label data was transcribed into observational 
specimen records and the data and metadata fields follow DarwinCore standards. The records were placed in an asci txt file (csv format) available for download as a supplemental file to this paper. Additionally, the dataset has been shared via an IPT installed on the OSAC server: http:/ / osac.oregonstate.edu/ipt), making the individual records retrievable via the GBIF data portal: http://www.gbif.org.

\section{Discussion}

Any novel observational record for a species has the potential to contribute meaningful biodiversity information about the species' geographic and temporal existence. In this case we report an observation for a particular species that had yet to be confirmed present in the state of Oregon. Although the absence or presence of a species within an artificial region such as a state or county has questionable biological importance, it has great social significance for tracking and communicating about biodiversity. Humans navigate their relative position so heavily based on these units that to convert biological distributions into sociopolitical units not only makes it easier to communicate about biodiversity but it facilitates resources (funding, labor, legislation, etc) that are commonly allocated via these same geopolitically units.

In fact, this novel record was produced by just such an endeavor, the Oregon Bee Project, a citizenscience based collaboration that seeks to raise awareness and knowledge specifically about the bees of Oregon. In this case, the synergy between professional scientists and non-professional entomologists is clear: the core observation was made by an interested and knowledgeable member of the public (S. Red-Laird), while the significance of that observation in terms of the overall Oregon bee-fauna and the historical records for the region were added by a professional scientist (Lincoln Best) and scientific institutions (Oregon State Arthropod Collection). Knowing for certain that Peponapis occurs in the state should also encourage others to seek it out and expand on the known distribution, which at the time of this publication is limited to Ashland Oregon.

Maintaining public interest and encouraging continued investment in citizen science programs can be challenging and a key are the non-monetary rewards of contributing to a worthwhile endeavor. In science, an important end product is 'scientific discovery': the realization of some truth or fact about the natural world that was previously unknown. By sharing the significance of an observation, or set of observations, with the individuals involved in generating them a citizen-science project re-invests in itself by sharing in the sense of discovery. In addition to discovery, science records its discoveries via publications (such as this) and including the individuals who contributed to those publications as co-authors or contributors is important so as to ensure that their real contributions towards making the scientific discoveries possible are not taken for granted or erased, which over time will underrepresent the challenges and man-power necessary to make large scale biodiversity discoveries possible.

\section{Acknowledgments}

Supported by the Foundation for Food and Agriculture Research under award number: 549024. The content of this publication is solely the responsibility of the authors and does not necessarily represent the official views of the Foundation for Food and Agriculture Research. 


\section{References}

Allchin CM (2018) Finding Pollinators to Fill In for Honeybees. New York Times, New York, 6 pp. Ayala R, Griswold T (2012) Two new species of the bee genus Peponapis, with a key to the North and Central American species (Hymenoptera: Apidae: Eucerini). Revista Mexicana de Biodiversidad 83: 396-406.

Hurd PD, Linsley EG (1964) The squash and gourd bees - genera Peponapis Robertson and Xenoglossa Smith - inhabigting America north of Mexico: (Hymenoptera: Apoidea). Berkeley, California: University of California, Berkeley.

Hurd PDJ, Linsley EG, Whitaker TW (1971) Squash and gourd bees (Peponapis, Xenoglossa) and the origin of the cultivated Cucurbita. Evolution 25: 218-234

Kleijn D, Winfree R, Bartomeus I, Carvalheiro LG, Henry M, Isaacs R, Klein A-M, Kremen C, M'Gonigle LK, Rader R, Ricketts TH, Williams NM, Lee Adamson N, Ascher JS, Báldi A, Batáry P, Benjamin F, Biesmeijer JC, Blitzer EJ, Bommarco R, Brand MR, Bretagnolle V, Button L, Cariveau DP, Chifflet R, Colville JF, Danforth BN, Elle E, Garratt MPD, Herzog F, Holzschuh A, Howlett BG, Jauker F, Jha S, Knop E, Krewenka KM, Le Féon V, Mandelik Y, May EA, Park MG, Pisanty G, Reemer M, Riedinger V, Rollin O, Rundlöf M, Sardiñas HS, Scheper J, Sciligo AR, Smith HG, Steffan-Dewenter I, Thorp R, Tscharntke T, Verhulst J, Viana BF, Vaissière BE, Veldtman R, Ward KL, Westphal C, Potts SG (2015) Delivery of crop pollination services is an insufficient argument for wild pollinator conservation. Nature Communications 6: 7414. doi:10.1038/ncomms8414 https: / / www.nature.com/articles/ncomms8414 - supplementary-information

López-Uribe M, Cane Jim H, Minckley Ron L, N. DB (2016) Crop domestication facilitated rapid geographical expansion of a specialist pollinator, the squash bee, Peponapis pruinosa. Proceedings of the Royal Society of London Series B Biological Sciences 283. doi:http: / / dx.doi.org/10.1098/rspb.2016.0443

Mathewson JA (1968) Nest construction and life history of the eastern cucurbit bee, Peponapis pruinosa (Hymenoptera: Apoidea). Journal of the Kansas Entomological Society 41: 251-261

Matias DMS, Leventon J, Rau A-L, Borgemeister C, von Wehrden H (2017) A review of ecosystem service benefits from wild bees across social contexts. Ambio 46: 456-467. doi:10.1007 / s13280-016-0844-z

McArthur LA, McArthur LL (2003) Oregon geographic names. Oregon Historical Society Press; Distributed by University of Washington Press, Portland Seattle, xiv, 1073 pages pp.

Telford HS, James MT (1973) Harold Rodney Dodge 1913-1973. Journal of Economic Entomology 66: 1358. doi:https:// doi.org/10.1093/jee/66.6.1358

Thomas J (2019) Snow Entomological Museum Collection. Version 26.25. University of Kansas Biodiversity Institute. Occurrence dataset https: / / doi.org/10.15468/ fhntpy. GBIForg. doi:https://doi.org/10.15468/fhntpy 